\title{
Produção e avaliação bromatológica de espécies forrageiras irrigadas com água salina
}

\author{
Sebastião B. de Carvalho Júnior ${ }^{2}$, Dermeval A. Furtado ${ }^{3}$, Valneide R. da Silva ${ }^{3}$, \\ Renilson T. Dantas ${ }^{4}$ Iracema da S. P. Lima² \& Vera L. A. de Lima ${ }^{3}$
}

\begin{abstract}
RESUMO
U ma das alternativas para a destinação de rejeito de dessalinizadores é a utilização em tanques de piscicultura e carcinocultura e posterior reúso na irrigação de culturas tolerantes a salinidade. 0 trabalho foi conduzido no município de Barra de Santa Rosa, PB, objetivando verificar a taxa de germinação da semente, brotação das mudas e características bromatológicas de maniçoba (Manihot glaziovii Muell Arg), erva-sal (Atriplex nummularia), flor de seda (Calotropis procera) e jureminha (D esmanthus virgatus), cultivadas e irrigadas com água excedentes de tanques de piscicultura e carcinocultura, oriundos de rejeito de dessalinizadores, com condutividade el étrica de 5.800 e $5.200 \mu \mathrm{S} \mathrm{cm}^{-1}$, respectivamente. A flor de seda e erva-sal apresentam maiores taxas de germinação $(96,0 \%)$ e brotação $(70,0 \%)$, respectivamente, seguidas da taxa de brotação da maniçoba $(62,0 \%)$ e da jureminha (51,0\%). Do total de mudas transplantadas 95,$0 ; 93,0 ; 82,7$ e 80,5\% das plantas de flor de seda, maniçoba, atriplex e jureminha, foram viáveis, respectivamente. As forrageiras apresentaram boa taxa de brotação e germinação e propagação e boa composição bromotologica, onde a jureminha e 0 atriplex apresentaram teor de proteína, matéria orgânica e energia bruta de 9,4 e 17,8\%; 95,0 e 76,3\% e 4.295,8 e 3.575,9 cal g-1 de energia bruta, respectivamente.
\end{abstract}

Palavras-chave: água residuária, alimentação animal, rejeito do dessalinizador

\section{Production and bromatological evaluation of forage species irrigated with saline water}

\begin{abstract}
One of the alternatives for the disposal of desalinization waste is its use in fishponds and shrimp production and later reuse for irrigation of crops tolerant to salinity. This work was conducted in Barra de Santa Rosa, PB, with the aim of verifying the rate of seed germination, sprouting and bromatologic characteristics of maniçoba (M anihot glaziovii Muell Arg), enva-sal (Atriplex nummularia), silk flower (Calotropis procera) and 'jureminha' (Desmanthus virgatus), cultivated and irrigated with excess water of fishponds and shrimp production, coming from desalinization waste, with electrical conductivity of 5,800 and 5,200 $\mu \mathrm{cm}^{-1}$, respectively. The silk flower and salt herb had higher rates of germination $(96.0 \%)$ and spouting $(70.0 \%)$, respectively, followed by the rate of sprouting of maniçoba (62.0\%) and jureminha (51.0\%). Of the total transplanted, 95.0, 93.0, 82.7 and $80.5 \%$ of plants of silk flower, maniçoba, atriplex and mimosa were viable, respectively. Forages had good rate of germination and sprouting and spreading, and good bromatological composition, where as 'jureminha' and atriplex presented protein content, organic matter and gross energy 9.4 and $17.8 \% ; 95.0$ and $76.3 \%$; and 4,295.8 and 3,575.9 cal g-1 of gross energy, respectively.
\end{abstract}

Key words: waste water, animal feed, residue of water desalinators

\footnotetext{
${ }^{1}$ Parte da Dissertação de Mestrado do primeiro autor

2Zootecnistas e Mestres em Engenharia Agrícola. E-mail: zoosbcjr@yahoo.com.br, iraspl@yahoo.com.br

3UAEA/UFCG. Av. Aprígio Veloso 882, CEP 58429-190, Campina Grande, PB. Fone: (83) 2101-1486. E-mail: dermeval@deag.ufcg.edu.br; rval707@yaho0.com.br; antuneslima@gmail.com

${ }^{4}$ UACA/U FCG. Fone: (83) 2101-1201. E-mail: renilson@dca.ufcg.edu.br
} 


\section{INTRODUÇÃO}

A caatinga oferece recursos forrageiros naturais, constituídos de plantas fisiologicamente adaptadas às condições particulares desse ecossistema, com bons valores nutritivos, palatabilidade e que tem mostrado grande potencial de espécies forrageiras que contribuem relevantemente para a composição e utilização das dietas dos animais (Alves et al., 2007; Marques et al., 2007; Costa et al., 2007; 2008), e estes recursos forrageiros naturais precisam ser valorizados, tanto para cultivo em campos de produção, como enriquecimento ou recuperação de áreas degradadas da caatinga.

A escassez de água, seja quantitativa ou qualitativa, tem sido uma constante, levando ao uso de dessalinização de água salobra, proveniente de poços perfurados no cristalino, com o objetivo de garantir água potável para as populações atingidas pelos efeitos da seca, porém este procedimento poderá trazer impactos ambientais severos em virtude da produção do rejeito, isto é, água com elevado teor de sais gerado durante o processo de dessalinização (Porto et al., 2006). Considerando o número de dessalinizadores existentes na região semiárida, estimado em 400 equipamentos, grande volume de rejeito está sendo gerado e, na quase totalidade dos casos, vem sendo depositado no solo sem receber qualquer tratamento, propiciando alto acúmulo de sais nas camadas superficiais do terreno (Porto et al., 1999) e que uma das alternativas para a destinação desse rejeito é a sua utilização em tanques de piscicultura e carcinocultura e posterior reúso na irrigação de culturas tolerantes a uma salinidade elevada e cultivada de acordo com um manejo adequado (Porto et al., 2001).

Entre essas culturas se destaca a erva-sal (Atriplex nummularia) por possuir mecanismos especializados de acumulação de sais no seu interior e de sua eliminação através das folhas. Para a irrigação das plantas halófitas, como a erva-sal (Atriplex nummalaria), pode usar água de rejeito de dessalinizadores em programas de reabilitação de solos em varias regiões áridas e semiáridas em processo de degradação ou sujeitas a desertificação, já que essas plantas são bem adaptadas a solos áridos e salinos (Barroso et al., 2006), capazes de tolerar condições climáticas adversas. O cultivo da ervasal pode ser uma alternativa viável para a região Nordeste, principalmente quando sua produção estiver atrelada à utilização dos rejeitos dos dessalinizadores de água salobra; o grande desafio é desenvolver e adaptar métodos para monitorar e avaliar o impacto do cultivo de halófitas sobre processos biológicos do solo (Porto et al., 2006) e analisar seu uso como forragem (Souto et al., 2005 e Alves et al., 2007).

A flor de seda (Calotropis procera) é uma espécie vegetal distribuída geograficamente nas regiões tropicais e subtropicais de todo o mundo; atualmente, encontra-se naturalizada na caatinga do sertão nordestino, onde é utilizada na alimentação animal (Marques et al., 2007). Oliveira (2005) estimou a produção de fitomassa de flor de seda em função da circunferência do caule e de espaçamentos no município de Patos, $\mathrm{PB}$, obtendo os seguintes resultados: no espaçamento de 0,5 x 0,$5 ; 1,0$ x 0,5 e 1,0 x 1,0, obteve-se 49,$40 ; 24,70$ e 12,30 t ha de biomassa, respectivamente, aos $10 \mathrm{~cm}$ de altura do solo e a $15 \mathrm{~cm}$ os dados de produção foram de 103,20; 51,60 e 25,80 $\mathrm{t} \mathrm{ha}^{-1}$, respectivamente. $\mathrm{O}$ uso da planta in natura na alimentação animal é limitada por algumas características da planta, como ligeira toxidade e segundo Marques et al. (2007) os teores de matéria seca, proteína bruta, energia bruta, cinzas, cálcio e fósforo (\% da matéria seca) do feno de flor de seda foram de 90,78; 9,40; 3,90; 12,55; 2,60 e 0,22, respectivamente.

Recentemente, o gênero Desmanthus tem despertado interesse como uma leguminosa forrageira para os trópicos e o semiárido. Entre as espécies desse gênero, destaca-se a Desmanthus virgatus (jureminha), por ser uma leguminosa arbustiva, perene, de larga ocorrência na região Nordeste, cujas rusticidades, agressividade e persistência, que permitem pastejo direto, formação de bancos de proteína, sozinha ou em consórcio com gramíneas, como também pode ser utilizada na forma de feno. A jureminha apresenta boa palatábilidade, rica em minerais e proteína e não apresenta princípio tóxico para os animais (Costa et al., 2008).

A maniçoba (Manihot glaziovii Muell Arg) é uma planta nativa da caatinga e com boa qualidade forrageira, por combinar grande resistência ao ambiente quente e seco da região e valor nutricional, o que lhe confere boa fonte de alimento para a dieta dos animais da região (Costa et al., 2007 e Medina et al., 2009). Esta forrageira tem alto grau de palatabilidade, possuem um razoável teor de proteína e boa produção de forragens (Porto et al., 2006); entretanto, deve haver restrição ao seu uso sob esta forma, quando em pastejo exclusivo, devido à possibilidade de provocar intoxicação. A fenação e a ensilagem, após trituração de todo o material forrageiro produzido, são os meios mais recomendados de utilização da maniçoba.

Costa et al. (2007) citam a maniçoba como boa forrageira para o semiárido, com níveis de fibra bruta e proteína bruta de 17,83 e 18,03\%, respectivamente. O risco de intoxicação (ácido cianídrico) é eliminado quando a planta é fornecida na forma de feno. A propagação de maniçoba pode ser efetivada por via seminífera ou assexuada. Entretanto, estudos verificaram que a propagação desta espécie através de estacas, apresenta dificuldades no enraizamento (Rodolfo Junior et al., 2009) e as sementes de maniçoba possuem um grande problema com dormência, que tem dificultado a propagação e cultivo da espécie. Também a perda de folhas no período seco revela a necessidade de manejo da forrageira, com cortes durante o período das chuvas. Objetivou-se, com este trabalho, verificar a produção das forrageiras nativas, taxa de germinação da semente, de brotação das mudas e analise das características bromatológicas de maniçoba, erva-sal, flor de seda e jureminha cultivadas utilizando-se água de tanques de piscicultura, oriunda de rejeito de dessalinizadores.

\section{MATERIAL E MÉTODOS}

O experimento foi realizado na fazenda experimental de Barra de Santa Rosa, no município de Barra de Santa Rosa, PB, região do semiárido paraibano, localizado entre as coordenadas 6 $6^{\circ} 43^{\prime} 12^{\prime \prime}$ de Latitude sul e $36^{\circ}$ 3' 39" de Longitude Oeste, vinculada ao PEASA - Programa de Estudos e Ações para 
o semiárido, da Universidade Federal de Campina Grande (UFCG) e à Fundação Parque Tecnológico da Paraíba. Pela classificação de Koppen (1936), o tipo climático da região é Bsh, semiárido quente com chuvas de verão/outono, e precipitação média em torno de $400 \mathrm{~mm}$ anuais.

As mudas de maniçoba e erva-sal foram produzidas por estaquia e as estacas coletadas na época do ano (setembro/ outubro) quando a escassez de água é elevada; uma estaca foi plantada em cada saco e cada estaca possuía no mínimo 5 gemas, das quais 3 eram enterradas no interior dos sacos de polietileno com terra. Enquanto as mudas de jureminha e flor de seda foram obtidas através de sementes; no caso específico da jureminha, as sementes foram submetidas ao tratamento de quebra de dormência, com a utilização de água quente (temperatura média de 80 a $90^{\circ} \mathrm{C}$ ) e escarificação; três sementes das mudas de jureminha e a flor de seda foram plantadas nos sacos de polietileno, com dimensões de $13 \mathrm{~cm}$ de diâmetro e $22 \mathrm{~cm}$ de altura; o substrato utilizado foi uma mistura de terra de subsolo e esterco bovino curtido na proporção de 2:1. As mudas foram acomodadas em ambiente coberto com sombrite e irrigadas a cada dois dias, com água proveniente dos tanques de piscicultura e carcinocultura.

Após 60 dias do plantio das mudas, analisaram-se as taxas de germinação das sementes de jureminha e flor de seda e as taxas de brotação das estacas de maniçoba e erva-sal, quando então foram transplantadas para o local definitivo. Para a implantação do experimento, realizaram-se a limpeza, o destocamento do terreno, a análise química e o preparo do solo. As forrageiras foram plantadas em 24 parcelas (6 repetições para cada espécie), e a área de cada parcela experimental foi de $6 \mathrm{x}$ $5 \mathrm{~m}$, com espaçamento entre parcelas de $2 \mathrm{~m}$; cada parcela foi composta de 6 linhas, com 5 plantas em cada linha, com espaçamento entre linhas e plantas de $1,0 \mathrm{~m}$; as covas possuíam profundidade média de $50 \mathrm{~cm}$ por 40 de diâmetro.

Por sua vez, as parcelas eram irrigadas duas vezes por semana, sempre no período da manhã, com água de tanques de carcinocultura e piscicultura, que eram coletadas em um tanque único, cuja origem foi o rejeito de dessalinizadores localizados na área do projeto; em cada planta era colocado um volume de água correspondente a $100 \%$ da evaporação registrada no período entre as irrigações e em quantidade suficiente para elevar a umidade do solo à sua capacidade de campo.

Durante o experimento e a cada 15 dias eram realizadas análises da água utilizada, em razão da mudança provocada pelos fatores físicos, químicos e biológicos da criação dos peixes e camarões, por meio da metodologia apresentada por EMBRAPA (1997). Realizou-se, após sessenta dias de plantio no campo, uma análise do índice de plantas sobreviventes na área experimental, para verificar a capacidade dessas forrageiras suportarem a irrigação com águas residuais e salinas; já aos seis meses de idade foi realizado o estudo do desenvolvimento das forrageiras, para analisar sua produção e composição química, seguido do corte de três plantas em cada parcela experimental, com a retirada de todo o material da parte aérea da planta, a uma altura superior a $50 \mathrm{~cm}$; referida etapa foi realizada apenas com a erva-sal e a jureminha, já que tinham desenvolvimento suficiente.
Para o caso da erva-sal o material colhido de cada planta foi classificado como lenha, caule, ramos e folhas; como caule considerou-se todo o material lenhoso com diâmetro máximo medindo cerca de $8,0 \mathrm{~mm}$ e, como lenha, todo o material lenhoso superior a este; por fim, denominou-se material forrageiro ao conjunto de caule, ramos e folhas, com metodologia adaptada de Porto et al. (2001); em seguida, retirou-se uma amostra de cada parte para análise bromatológica. No caso da jureminha foi realizada a análise da planta inteira, em razão da impossibilidade de se dividir a planta em partes.

As análises bromatológicas realizadas foram a matéria seca (MS), proteína bruta (PB), matéria orgânica (MO), cinza (CZ), fibra em detergente neutro (FDN), fibra em detergente ácido (FDA), extrato etéreo (EE) e energia bruta (EB) conforme metodologia descrita por Silva \& Queiroz (2002).

O delineamento experimental para a análise da brotação/ germinação e taxa de sobrevivência, foi em blocos ao acaso, com quatro tratamentos e seis repetições, sendo que os dados foram submetidos à análise de variância e ao teste de Tukey (5\% de probabilidade). Realizaram-se todas as análises utilizando-se o software SAS (1996).

\section{RESULTADOS E DISCUSSÃO}

A composição química da água proveniente dos tanques de piscicultura (TP) e dos tanques de carcinocultura (TC) está apresentada na Tabela 1; os valores de $\mathrm{pH}$ estão dentro do padrão para o cultivo de plantas, porém a condutividade elétrica mostra valores elevados, demonstrando severas restrições para o uso desta água em irrigação, de acordo com as diretrizes sobre a qualidade da água de Ayres \& Westcot (1991), segundo os quais essas diretrizes constituem o primeiro passo para assinalar limitações em qualidade de determinada fonte de água; portanto, é necessário criar condições de manejo para tornar possível o uso dessa água. Entre as alternativas para adequar o uso da água salina ao processo da irrigação, pode-se realizar a mistura de águas, aplicação de lâminas de lixiviação, aumento da frequiência de irrigação e cultivo de plantas tolerantes a salinidade.

Tabela 1. Valores médios da análise da água proveniente dos tanques de piscicultura e carcinocultura

\begin{tabular}{|c|c|c|}
\hline \multirow{2}{*}{ Analise da água } & \multicolumn{2}{|c|}{ Tanque } \\
\hline & Piscicultura & Carcinocultura \\
\hline $\mathrm{pH}$ & 7,72 & 7,66 \\
\hline Condutividade elétrica ( $\mu \mathrm{S} \mathrm{cm}^{-1}$ ) & 5.800 & 5.200 \\
\hline Cálcio $\left(\mathrm{m} \mathrm{mol}_{\mathrm{c}} \mathrm{L}^{-1}\right)$ & 13,76 & 11,70 \\
\hline Magnésio $\left(\mathrm{m} \mathrm{mol}_{\mathrm{c}} \mathrm{L}^{-1}\right)$ & 44,41 & 40,35 \\
\hline Sódio ( $\left.\mathrm{m} \mathrm{mol}_{\mathrm{c}} \mathrm{L}^{-1}\right)$ & 22,07 & 19,31 \\
\hline Potássio (m mol $\left.\mathrm{c}^{-1}\right)$ & 1,84 & 0,82 \\
\hline Carbonato $\left(\mathrm{m} \mathrm{mol}_{\mathrm{c}} \mathrm{L}^{-1}\right)$ & 0,00 & 0,24 \\
\hline Bicarbonatos ( $\left.\mathrm{m} \mathrm{mol}_{\mathrm{c}} \mathrm{L}^{-1}\right)$ & 2,80 & 3,43 \\
\hline Cloretos ( $\left.\mathrm{m} \mathrm{mol}_{\mathrm{c}} \mathrm{L}^{-1}\right)$ & 69,75 & 66,50 \\
\hline Sulfetos $\left(\mathrm{m} \mathrm{mol}_{\mathrm{c}} \mathrm{L}^{-1}\right)$ & Presença & Presença \\
\hline Relação de adsorção de sódio(RAS) & 4,10 & 3,78 \\
\hline
\end{tabular}


Em relação aos íons específicos, constatou-se elevado teor de cloreto; este íon se desloca facilmente, podendo ser absorvido pelas raízes e translocado às folhas, passível de provocar queimaduras e necrose em folhas. Segundo Ayres \& Westcot (1991) os danos ocorrem primeiro nas pontas das folhas para logo se deslocar, à medida em que progride a toxicidade, ao longo das bordas em que a necrose vem acompanhada, quase sempre, pela desfolhação prematura o que, no caso de plantas forrageiras, é indesejável, uma vez que as folhas representam o principal componente da forragem.

$\mathrm{O}$ valor médio das taxas de germinação das sementes de jureminha e flor de seda e das taxas de brotação das estacas de maniçoba e erva-sal está apresentado na Tabela 2, na qual se observa diferença significativa entre as quatro espécies ( $\mathrm{P}$ $>0,05)$. Verifica-se que a flor de seda e erva-sal apresentou maiores taxas de germinação $(96,0 \%)$ e brotação $(70,0 \%)$, respectivamente, seguidas da taxa de brotação da maniçoba $(62,0 \%)$ e germinação da jureminha $(51,0 \%)$. O maior índice de germinação da flor de seda se deve à pureza das sementes, que ficam armazenadas em seus casulos e seu alto poder germinativo, fato também comprovado por Silva et al. (2009), ao verificarem que 82 e $87 \%$ das sementes da flor de seda germinaram, ao serem cultivadas em areia e nas temperaturas de 25 e $27^{\circ} \mathrm{C}$.

Tabela 2. Valores médios de brotação das estacas de maniçoba e erva sal e de germinação das sementes de jureminha e flor de seda

\begin{tabular}{|c|c|c|c|c|}
\hline \multirow{2}{*}{ Espécies } & \multicolumn{2}{|c|}{ No de plantas na área } & \multicolumn{2}{|c|}{ Germinação/brotação } \\
\hline & $\mathrm{n}^{0}$ mudas & $\%$ mudas & $\mathrm{n}^{0}$ mudas & $\%$ mudas \\
\hline Maniçoba & 426 & 100 & 264 & $62,0 \mathrm{c}$ \\
\hline Erva-sal & 460 & 100 & 322 & $70,0 \mathrm{~b}$ \\
\hline Jureminha & 460 & 100 & 234 & $51,0 \mathrm{~d}$ \\
\hline Flor de seda & 460 & 100 & 436 & 96,0 a \\
\hline
\end{tabular}

*Médias nas colunas seguidas de letras diferentes diferem entre si pelo teste de Tukey a $5 \%$ de probabilidade.

A jureminha apresentou a menor taxa de germinação, mesmo com a adoção do processo de quebra de dormência das sementes, demonstrando que as ultimas podem necessitar de outros métodos para aumentar a germinação. Jamwal \& Dutt, (1995) pesquisando a germinação sementes de Sesbani sesban, citam uma taxa de germinação de $37,5 \%$ para sementes sem escarificação, aumentando para até $86 \%$ após escarificação pela imersão em água fervente por 60 segundos e $79 \%$ após imersão em ácido sulfúrico por $15 \mathrm{~min}$, portanto com tratamento a base de água fervente superior ao do presente trabalho.

Embora ocorrendo diferença significativa $(p>0,05)$ entre a maniçoba e a erva-sal, plantadas através da estaquia, ambas apresentaram índices de brotação acima de 50\%, que podem ser considerados adequados, fato que se deve à época em que se realizaram os cortes para a confecção das mudas, no período seco do ano, quando as plantas se apresentam com reservas para reiniciar suas atividades de crescimento vegetativo por ocasião da época chuvosa (Pimenta Filho et al., 2004); além disso, as matrizes eram plantas jovens, com pouco mais de um ano.
Verifica-se, na Tabela 3, o número de plantas cultivadas existentes na unidade experimental, após 60 dias da implantação, observando-se que 93,$3 ; 80,5 ; 82,7$ e $95 \%$ das plantas de maniçoba, erva-sal, jureminha e flor de seda, respectivamente, sobreviveram, demonstrando que, mesmo sendo irrigadas com uma água considerada de qualidade inferior, conseguiram ótimo índice de sobrevivência. Não houve diferença significativa $(p>0,05)$ entre maniçoba e a flor de seda, que diferiram da erva-sal e jureminha; as duas últimas espécies não diferiram entre si ( $p>0,05)$. Araújo et al. (2007) utilizaram esgoto tratado na produção de mudas do bioma caatinga e constatou que estas tiveram crescimento médio maior quando comparadas com plantas cultivadas e irrigadas com água de abastecimento urbano.

Tabela 3. Número de plantas cultivadas na área experimental no município de Barra de Santa Rosa, PB

\begin{tabular}{lcccccc}
\hline \multirow{2}{*}{ Espécies } & \multicolumn{2}{c}{ No de plantas na área } & & \multicolumn{2}{c}{ Taxa de sobrevivência } \\
\cline { 2 - 3 } \cline { 5 - 6 } Mo mudas & no mudas & & no mudas & $\%$ mudas \\
Maniçoba & 180 & 100 & & 168,0 & $93,3 \mathrm{a}$ \\
Erva-sal & 180 & 100 & & 145,0 & $80,5 \mathrm{~b}$ \\
J ureminha & 180 & 100 & & 149,0 & $82,7 \mathrm{~b}$ \\
Flor de seda & 180 & 100 & & 149,0 & $95,0 \mathrm{a}$ \\
\hline
\end{tabular}

*Médias nas linhas seguidas de letras diferentes diferem entre si pelo teste de Tukey a $5 \%$ de probabilidade

A flor de seda, apesar de não ser planta nativa do semiárido nordestino, apresentou a maior percentagem de sobrevivência, demonstrando alta capacidade de naturalização, alcançada ao longo dos anos, sendo comum nesta região (Silva et al., 2009). A maniçoba mostrou que também é uma planta altamente resistente às condições ambientais do semiárido e à salinidade (Porto et al., 2001). A erva-sal, apesar de ser uma planta altamente tolerável à salinidade (Barroso et al., 2006), apresentou taxa de sobrevivência menor, semelhante aos valores encontrados para jureminha.

$\mathrm{Na}$ Tabela 4 se apresentam os valores da produção de matéria verde e a proporção dos componentes da erva-sal, com 180 dias após o plantio. Proporcionalmente, as folhas corresponderam à maior parte do peso da planta, em torno de $77,8 \%$, sinal de que houve uma produção de matéria verde considerável, o que faz da erva-sal uma planta com potencial forrageiro destacado, pela alta relação folha-caule, considerando-se que cada planta produziu em média $12,6 \mathrm{~kg}$ e foram plantadas a 1,0 m, entre linhas e colunas, o que poderia perfazer o total de 10.000 plantas, projetando uma produção por hectare de $126.000 \mathrm{~kg}$ de matéria verde, no período de 8 meses.

Tabela 4. Produção de massa verde e percentual produzido por parte das plantas de erva-sal

\begin{tabular}{ccc}
\hline Parte da planta & $\begin{array}{c}\text { Produção de matéria } \\
\text { verde }(\mathbf{k g})\end{array}$ & $\begin{array}{c}\text { Proporção em relação ao } \\
\text { total da planta }(\%)\end{array}$ \\
Folha & 9,8 & 77,8 \\
Ramo & 2,3 & 18,3 \\
Caule & 0,4 & 3,2 \\
Lenha & 0,08 & 0,6 \\
Total & 12,6 & 100 \\
\hline
\end{tabular}


O valor de $12,6 \mathrm{~kg}$ por planta foi inferior aos relatados por Porto et al. (2006), que em trabalhos com diferentes volumes de efluentes encontraram um valor médio de $16,8 \mathrm{k}$ por planta, quando colhidas aos 12 meses de idade; quanto à produção total, os valores estão bastante superiores aos relatados pelos autores mencionados, fato que pode ser explicado pelo espaçamento entre as covas, adotado no presente trabalho, que foi de 1,0 x 1,0 m, enquanto o dos autores foi de 4,0 x 4,0 $\mathrm{m}$. Por outro lado, a maior proporção de folhas e ramos que pode ser utilizada na alimentação animal em detrimento de caules pode beneficiar a alimentação animal visto que os referidos componentes apresentam melhor valor nutritivo, refletido nos valores de composição químico-bromatológica da matéria seca (Souto et al., 2005; Barroso et al., 2006 e Alves et al., 2007). Em termos de nutrição animal, principalmente para monogástricos, a baixa percentagem de caule e lenha, que é a parte mais fibrosa e muito pouca aproveitada pelos animais, confere à erva sal características que a tornam uma alternativa amplamente viável para solos salinos ou irrigados com águas residuárias e salinas.

As proporções de folhas e ramos encontradas no estudo foram superiores às observadas por Porto et al. (2001), para plantas de erva-sal cortadas com um ano, que relatam valores de 56,7 e 12,3\%, respectivamente; para as proporções de caule e lenha, os autores citam valores superiores (12,7 e $18,3 \%$, respectivamente) devido, provavelmente, à idade do corte. Barroso et al. (2006), estudando níveis de quantidade de água salobra na irrigação da erva-sal, encontraram em torno de $50 \%$ de produção de folha para a planta.

A Tabela 5 engloba os valores da produção média de massa verde da jureminha; observa-se predominância dos ramos em detrimento das folhas, fato que pode ser justificado em razão da queda natural que ocorre nas folhas da jureminha e também pelo seu crescimento vegetativo, que tende a se espalhar pela parcela, sobretudo na fase inicial de crescimento; esta queda nas folhas também pode ser atribuída à sensibilidade da planta em relação à presença de elevado teor de cloreto contido na água; como esses ramos têm diâmetro inferior a $8 \mathrm{~cm}$, também podem ser utilizados na ração animal, de forma especial na de ruminantes.

Tabela 5. Média de massa verde e percentual produzido por parte das plantas de jureminha

\begin{tabular}{ccc}
\hline Parte da planta & $\begin{array}{c}\text { Produção de matéria } \\
\text { verde }(\mathrm{kg})\end{array}$ & $\begin{array}{c}\text { Proporção em relação ao } \\
\text { total da planta (\%) }\end{array}$ \\
Folha & 0,113 & 11,7 \\
Ramo & 0,781 & 80,3 \\
Caule & 0,078 & 8,0 \\
Total & 0,973 & 100 \\
\hline
\end{tabular}

Na Tabela 6 se encontram os valores da composição química das plantas de erva-sal e jureminha observando-se que, com exceção do extrato etéreo, ocorreu diferença significativa $(p>0,05)$ entre todos os outros valores; em referência à percentagem de matéria seca, pode-se justificar o menor valor para a erva-sal em razão da alta percentagem de folhas nas plantas e baixa percentagem de ramos, contrário ao que aconteceu com a jureminha.

A erva-sal apresentou bons valores nutricionais; segundo Barroso et al. (2006) as plantas de erva-sal apresentam bom valor de proteína bruta, comparável às boas forrageiras; a jureminha mostrou um valor para $\mathrm{PB}$ pouco abaixo da ervasal, mas também pode ser considerada forragem de boa qualidade.

Os resultados obtidos para matéria orgânica (MO), fibra em detergente neutro (FDN) e fibra em detergente ácido (FDA) da erva-sal, se mostram inferiores aos valores da jureminha; isto pode ter acontecido em razão da menor percentagem de ramos e caule produzida.

Os dados obtidos para cinzas e energia bruta da jureminha foram semelhantes aos de Costa et al. (2007), e os valores de fibra em detergente neutro e fibra em detergente ácido da jureminha podem ser considerados elevados para uso na alimentação de monogástricos, e este valor pode ser justificado pelo fato do material analisado ter sido basicamente composto de ramos e caule e com pouca folha.

A proteína bruta da jureminha foi de $9,4 \%$, inferior aos valores citados por Costa et al. (2007), sendo que os valores de PB nas duas forrageiras foram superiores aos valores relatados por Botrel et al. (2002), avaliando diversos tipos de forrageiras. Considerando a importância do teor de proteína bruta, Milfort \& Minson (1996) consideram que 7,0\% é menor nível que uma forrageira deve ter para um bom funcionamento dos processos fisiológicos e, que um alimento tenha fermentação ruminal adequada. Santos et al. (2001) citam que teores de proteína bruta inferiores a $7 \%$ são limitantes à produção animal devido a baixos consumos voluntários, menores coeficientes de digestibilidade e balanço negativo de nitrogênio.

Encontram-se, na Tabela 7, os valores médios da composição química da erva-sal e suas partes; observa-se que as partes da erva-sal apresentaram diferença estatística $(p>0,05)$ na sua composição; os teores de MS variaram significativamente para a planta inteira e para as partes da planta, em que a planta inteira apresenta maior valor e as folhas valor inferior às demais partes; para PB, ocorreu uma concentração maior nas folhas quando comparadas com as demais partes, em razão da maior concentração de nutrientes na folha.

O teor de proteína bruta médio das folhas foi de 18,7\%, confirmando que as folhas da erva-sal são detentoras de bons

Tabela 6. Composição bromotológica da planta inteira de erva sal e jureminha

\begin{tabular}{ccccccccc} 
Espécie & $\%$ MS & $\%$ PB & $\%$ Cinza & $\%$ MO & $\%$ FDN & $\%$ FDA & $\%$ EE & EB (cal g-1) \\
JPI & $61,41 \mathrm{a}$ & $9,4 \mathrm{~b}$ & $4,6 \mathrm{a}$ & $95,4 \mathrm{a}$ & $72,6 \mathrm{a}$ & $52,8 \mathrm{a}$ & $10,1 \mathrm{a}$ & $4295,8 \mathrm{a}$ \\
API & $57,72 \mathrm{~b}^{* *}$ & $17,8 \mathrm{a}^{* *}$ & $23,7 \mathrm{~b}^{* *}$ & $76,3 \mathrm{~b}^{* *}$ & $49,2 \mathrm{~b}^{* *}$ & $21,7 \mathrm{~b}^{* *}$ & $10,6 \mathrm{a} \mathrm{ns}$ & $3575,9 \mathrm{~b}^{* *}$ \\
CV & 0,02 & 1,64 & 2,54 & 0,36 & 0,82 & 1,44 & 4,83 & 0,34 \\
\hline
\end{tabular}

MS - matéria seca; PB - proteína bruta; MO - matéria orgânica; FDN - fibra em detergente neutro; FDA - fibra em detergente ácido; EE - extrato etéreo; EB - energia bruta; JPI: Jureminha planta inteira; API: Erva sal planta inteira; ** Teste Tukey $1 \%$ de probabilidade; ns não significativa; Letras iguais nas colunas não diferem estatisticamente 
Tabela 7. Valores médios da matéria seca (MS), proteína bruta (PB), cinzas, materia orgânica (MO), fibra em detergente neutra (FDN), fibra em detergente ácida (FDA), extrato etéreo (EE) e energia bruta das partes da planta de erva-sal

\begin{tabular}{ccccccccc}
\hline Parte da planta & (\%) MS & (\%) PB & (\%)Cinzas & (\%)MO & (\%) FDN & (\%) FDA & (\%) EE & EB (cal g $\left.{ }^{-1}\right)$ \\
API & $57,72 a^{* *}$ & $17,8 a^{* *}$ & $23,7 b^{* *}$ & $76,3 c^{* *}$ & $49,2 c^{* *}$ & $21,7 c^{* *}$ & $10,6 a$ ns & $3575,9 b^{* *}$ \\
AR & $51,10 \mathrm{~b}$ & $8,5 b$ & $5,7 \mathrm{c}$ & $94,2 \mathrm{~b}$ & $75,6 \mathrm{~b}$ & $47,6 \mathrm{~b}$ & $8,8 \mathrm{a}$ & $4250,1 \mathrm{a}$ \\
AF & $45,15 \mathrm{c}$ & $18,7 \mathrm{a}$ & $27,2 \mathrm{a}$ & $72,8 \mathrm{~d}$ & $38,8 \mathrm{~d}$ & $13,0 \mathrm{~d}$ & $10,5 \mathrm{a}$ & $2792,6 \mathrm{c}$ \\
AC & $24,92 \mathrm{~d}$ & $7,0 \mathrm{c}$ & $3,1 \mathrm{~d}$ & $96,8 \mathrm{a}$ & $85,5 \mathrm{a}$ & $56,2 \mathrm{a}$ & $9,5 \mathrm{a}$ & $4320,7 \mathrm{a}$ \\
CV & 0,03 & 2,30 & 2,92 & 0,51 & 0,85 & 1,56 & 8,18 & 1,19 \\
\hline
\end{tabular}

MS - matéria seca; PB - proteína bruta; MO - matéria orgânica; FDN - fibra em detergente neutro; FDA - fibra em detergente ácido; EE - extrato etéreo; EB - energia bruta; API: erva-sal planta inteira; AR: erva-sal ramo; AF: erva-sal folha; AC: erva-sal caule; ${ }^{* *}$ significativo a $1 \%$ de probabilidade; ${ }^{\text {ns }}$ não significativo

teores de proteína bruta e podem ser comparados com as de algumas leguminosas e outras espécies frequentemente utilizadas na alimentação animal, como a leucena, gliricídia, guandu forrageiro e a maniçoba que, em geral, normalmente apresentam entre 12 e $22 \%$ de proteína bruta.

Em comparação com as gramíneas tropicais, em que os valores médios encontrados se situam comumente, entre 5 a $10 \%$, as folhas da erva-sal podem ser consideradas uma fonte de proteína para a alimentação animal e contribuir para elevar a proteína bruta de dietas à base de volumosos de baixa qualidade. Os valores encontrados neste estudo são superiores aos de Barroso et al. (2006).

Os teores de matéria mineral (MM) também se mantiveram elevados nas folhas, confirmando ser esta a principal fonte de eliminação dos sais requerendo, então, cuidados com os teores de MM de dietas com grande proporção de folhas de erva-sal, a ponto de não permitir que teores elevados de sais sejam comprometedores do consumo animal.

Para os resultados encontrados nas análises da FDN e FDA, o caule se apresenta com valores superiores aos das demais partes da planta, fato este relacionado com o elevado teor de fibra, encontrado nesta parte da planta; já as folhas, por serem um material menos fibroso, apresentaram menor concentração de FDN e FDA.

Os valores de FDN e FDA para ramos e caules se mostraram semelhantes aos valores encontrados por Barroso et al. (2006) ou seja, uma média de 78,76\% de FDN e $43,66 \%$ de FDA para ramos e 83,04 de FDN e 57,23 de FDA para caule.

Os dados encontrados neste estudo para PB e FDN das folhas, ramos e caule, conferem com os resultados obtidos por Porto et al. (2001), podendo ser enquadrados no grupo das forrageiras consideradas nobres quanto ao seu valor nutricional que tem, como padrão, a alfafa.

\section{CONCLUSÕES}

1. As forrageiras apresentaram boa taxa de brotação e germinação mostrando boa eficiência de propagação.

2. As forrageiras estudadas são resistentes às condições de semiárido, quando irrigadas com água provenientes de tanques de piscicultura e carcinocultura.

3. A jureminha e a erva-sal têm bom potencial forrageiro, mesmo irrigadas com água contendo alto teor de sais.

\section{LITERATURA CITADA}

Alves, J. N.; Araújo, G. G. L.; Porto, E. R.; Castro, J. M..; Souza, L. C. Feno de erva-sal (Atriplex nummularia Lindl) e palma forrageira (Opuntia ficul Mill) em dietas para caprinos e ovinos. Revista Cientifica de Produção Animal, v.9, n.1, p.4352, 2007.

Ayres, R. S.; Westcot, D. W. A qualidade da água na agricultura. Campina Grande: UFPB, 1991. 215p.

Araújo, B. A.; Dantas Neto, J.; Lima, V. L. A. de; Santos, J. S. Uso do esgoto doméstico tratado na produção de mudas de espécies florestais da caatinga. Principia, n.15, v.2, p.48-53, 2007.

Barroso, D. D.; Araújo, G. G. L.; Porto, E. R.; Porto, F. R. Produtividade e valor nutritivo das frações forrageiras da Erva-Sal (Atriplex Nummularia) irrigada com quatro diferentes volumes de efluentes da criação de tilápia em água salobra. Revista Agropecuária Técnica, v.27, n.1, p.43-48, 2006.

Botrel, M. A.; Alvin, M. J.; Ferreira, R. D.; Xavier, D. F. Potencial forrageiro de gramíneas de baixas temperaturas e altitude elevada. Pesquisa Agropecuaria Brasileira, v.37, n.3, p-393398, 2002.

Costa, F. G. P.; Silva, J. H. V.; Lima Neto, R. C.; Quirino, B. J. S.; Rodrigues, A. E. Utilização do feno de jureminha (Desmanthus virgatus) na alimentação de frangos caipiras. Agropecuária Técnica, v.29, n.1-2, p.11-16, 2008.

Costa, F. G. P.; Souza, W. G.; Silva, J. H. V.; Goulart, C. C.; Martins, T. D. D. Avaliação do feno de maniçoba (Manihot pseudoglaziovii Paz \& Hoffman) na alimentação de aves caipiras. Revista Caatinga, v.20, n.3, p.42-48, 2007.

EMBRAPA - Empresa Brasileira de Pesquisa Agropecuária. Manual de métodos de análise do solo. 2.ed. Rio de Janeiro: Embrapa - CNPS, 1997. 247p.

Jamwal, U.; Dutt, A.K. Germination response of seeds of Sesbania sesban provenances to different presowing treatments. Indian Forester, v.121, p.1169-1171, 1995.

Koppen, W. Dasa geographi SC system der klimate. In: Koppen. W.; Geiger, R. Handbuch der klimatologia. Berlim: Gerdrulier Borntraeger, v.1, Part c, 1936. 44p.

Marques, A. V. M. S.; Costa, R. G.; Silva, A. M. A.; Pereira Filho, J. M.; Madruga, M. S.; Lira Filho, G.E. Rendimento, composição tecidual e musculosidade da carcaça de cordeiros Santa Inêz com diferentes níveis de feno de flor-de-seda na dieta. Revista Brasileira de Zootecnia, v.36, n.3, p.610-617, 2007. 
Medina, F. T.; Cândido, M. J. D.; Araújo, G. G. L.; Barroso, D. D.; Cruz, M. C. S. Silagem de maniçoba associada a diferentes fontes energéticas na alimentação de caprinos: desempenho animal. Acta Scientiarum Animal Sciences, v.31, n.2, p.51-154, 2009.

Milford, R.; Minson, D. J. Intake of tropical pasture species. In: International Grassland Congress, 9., 1966, São Paulo. Proceedings... São Paulo: Alarico, 1966. p.815-822.

Oliveira, V. M. Estimativa da produção de biomassa de Calotropis procera (Ait) R. BR. e avaliação de sua composição química no estado da Paraíba. Revista Cientifica de Produção Animal, v.7, n.1, p.37-38, 2005.

Pimenta Filho, E. C.; Silva, D. S.; Medeiros, A. N.; Andrade, A. P. Produção, conservação e utilização de forrageiras do Semiárido. Areia: SEBRAE/PB-CCA/UFPB, 2004. 38p.

Porto, E. R.; Amorim, M. C. C. de; Araújo, O. J.; Silva Júnior, L. G. A. Aproveitamento dos rejeitos da dessalinização. A captação de água de chuva: Base para viabilização do semi-árido brasileiro. In: Simpósio Sobre Captação de Água de Chuva no Semiárido Brasileiro, 1, 1997, Petrolina. Anais... Petrolina: Embrapa Semi-Árido/IRPAA/IRCSA, 1999. p.51-57.

Porto, E. R.; Amorim, M. C. C. de; Dutra, M. T.; Paulino, R. V.; Brito, L. T .L.; Matos, A. N. B.; Rendimento da atriplex numulária irrigada efluentes da criação de tilápias em rejeito da dessalinização de água. Revista Brasileira de Engenharia Agrícola e Ambiental, v.10, n.1, p.97-103, 2006.
Porto, E. R.; Amorim, M. C. C. de; Silva Júnior, L. G. A. Uso do rejeito da dessalinização de água salobra para irrigação da erva-sal (Atriplex nummularia). Revista Brasileira de Engenharia Agrícola e Ambiental, v.5, n.1, p.111-114, 2001.

Rodolfo Junior, F.; Barreto, L. M. G.; Lima, A. R.; Campos, V. B.; Buriti, E. S. Tecnologia alternativa para a quebra da dormência de sementes de maniçoba (Manihot glaziovii, Euphorbiaceae). Revista Caatinga, v.22, n.1, p.20-26, 2009.

Santos, E. A.; Silva, D. S.; Queiroz Filho, J. L. Composição química do capim-elefante cv. Roxo cortado em diferentes alturas. Revista Brasileira de Zootecnia, v.30, n.1, p.262-266, 2001.

SAS Institute. User's guide: Statistics. Versão 6.12. Cary: North Carolina State University, 1996, 956p.

Silva, D. J. Queiroz, A. C. Análise de alimentos: Métodos químicos e biológicos. 3.ed. Viçosa: UFV, 2002. 235p.

Silva, J. R.; Medeiros, M. A. A.; Nascimento, I. J. B.; Ribeiro, M. C. C.; Nunes, G. H. S. Temperatura e substrato na germinação de sementes de Flor-de-seda. Revista Caatinga, v.22, n.1, p.175-179, 2009.

Souto, J. C. R.; Araújo, G. G. L.; Silva, D. S.; Porto, E. R.; Turco, S. H. N.; Medeiros, A. N. Desempenho produtivo de ovinos alimentados com dietas contendo níveis crescentes de feno de erva sal (Atriplex nummularia Lindl.). Revista Ciência Agronômica, v.36, n.3, p.376-381, 2005. 